\title{
The trabecular meshwork: structure, function and clinical implications. A review of the literature.
}

\author{
$\underline{\text { J. Buffault }^{a}}, \underline{\text { A. Labbé }}{ }^{\text {abc d }}, \underline{\text { P. Hamard }}{ }^{\text {a }}, \underline{\text { F. Brignole-Baudouin }}{ }^{\text {d e }}, \underline{\text { C. Baudouin }}{ }^{\text {abcd }}$
}

a

\author{
Ophthalmology Department, Centre Hospitalier National d'Ophtalmologie des \\ b \\ Quinze-Vingts, IHU FOReSIGHT, 28, rue de Charenton, 75012 Paris, France \\ Ophthalmology Department, hôpital Ambroise-Paré, IHU FOReSIGHT, AP-HP, 9, \\ avenue Charles-De-Gaulle, 92100 Boulogne-Billancourt, France \\ Université de Versailles Saint-Quentin-en-Yvelines, 78000 Versailles, France \\ Inserm, CNRS, Institut de la Vision, Sorbonne University, 17, rue Moreau, 75012 \\ Paris, France \\ Laboratory Department, Centre Hospitalier National d'Ophtalmologie des Quinze- \\ Vingts, IHU FOReSIGHT, 28, rue de Charenton, 75012 Paris, France
}

$\mathrm{c}$

\begin{abstract}
Glaucoma is a blinding optic neuropathy, the main risk factor for which is increased intraocular pressure (IOP). The trabecular meshwork, located within the iridocorneal angle, is the main pathway for drainage of aqueous humor $(\mathrm{AH})$ out of the eye, and its dysfunction is responsible for the IOP elevation. The trabecular meshwork is a complex, fenestrated, threedimensional structure composed of trabecular meshwork cells (TMC) interdigitated into a multilayered organization within the extracellular matrix (ECM). The purpose of this literature review is to provide an overview of current understanding of the trabecular meshwork and its pathophysiology in glaucoma. Thus, we will present the main anatomical and cellular bases for the regulation of aqueous humor outflow resistance, the pathophysiological mechanisms involved in trabecular dysfunction in the various types of glaucoma, as well as current and future therapeutic strategies targeting the trabecular meshwork.
\end{abstract}

Keywords: trabecular meshwork; glaucoma; intraocular pressure; ocular hypertension; iridocorneal angle; trabecular meshwork cells; aqueous humor; primary open angle glaucoma; secondary glaucoma; steroid-induced glaucoma; pigmentary glaucoma; pseudoexfoliative glaucoma; glaucoma medications; trabeculoplasty; glaucoma surgery 


\section{Outline}

Introduction

Structure and function

Anatomy

Trabecular meshwork cells

Extracellular matrix

Aqueous outflow and regulation of intraocular pressure

Trabecular degeneration in glaucoma

Primary open angle glaucoma

Angle closure glaucoma

Steroid-induced glaucoma

Pigmentary glaucoma

Pseudoexfoliative glaucoma

Uveitic glaucoma

Trabecular toxicity of glaucoma medications

Therapeutic approaches

Medical

Laser

Surgical

Filtering surgery

Trabecular MIGS

Perspectives

New techniques under investigation

Trabecular protection

Cell therapy

\section{Conclusion}




\section{Introduction}

Glaucoma is a blinding optic neuropathy affecting approximately 70 million individuals world-wide [1]. Its main risk factor is elevated intraocular pressure (IOP) [2]. The trabecular meshwork, located within the iridocorneal angle, constitutes the main pathway for drainage of aqueous humor out of the eye. It is a fenestrated three-dimensional structure composed of trabecular meshwork cells (TMC) within a multi-layered extracellular matrix (ECM)[3]. The trabecular meshwork controls the IOP by regulating outflow of aqueous humor from the anterior chamber of the eye into the adjacent Schlemm's canal (SC) and then via aqueous vein collector channels into the venous system. Dysfunction of the trabecular meshwork is the cause of IOP elevation. The purpose of this literature review is to provide an overview of current understanding of this complex structure, which plays a key role in the pathophysiology of glaucoma.

\section{Structure and function}

Anatomy

Embryologically, the trabecular meshwork is derived from a mixed mesodermal origin and a wave of mesenchymal cells coming from the neural crest between the $15^{\text {th }}$ and $20^{\text {th }}$ week of development $[4,5]$.

It is a sieve-like structure which acts as a filter between the anterior chamber and Schlemm's canal (SC), a circular canal which collects the aqueous and evacuates it into the extraocular circulation (figure 1a).

The trabecular meshwork, which bridges the scleral sulcus, thus isolating SC within the scleral sulcus, inserts anteriorly into the peripheral cornea at the level of Schwalbe's line, while posteriorly, the trabecular lamellae are connected to the junction between the ciliary body, iris and scleral spur.

We make a distinction between two different functional portions: the anterior, or nonfiltering, trabecular meshwork, which is not in communication with $\mathrm{SC}$, and the posterior, or filtering, trabecular meshwork, which is in communication with SC [6].

The anterior trabecular meshwork is a transition zone between Schwalbe's line and the posterior trabecular meshwork. It is formed of 4 to 5 trabecular lamellae covered with TMC. Within the transition zone between the non-filtering and filtering trabecular meshwork, electron microscopy reveals spaces organized into microscopic canals whose significance is poorly understood but which may serve in fluid transport or access to accessory cells necessary for cellular regeneration.

The posterior trabecular meshwork is known as filtering, since it is in communication with SC. It represents the trabecular filter proper. It consists of three anatomically distinct regions, from inner to outer: the uveal meshwork, the corneoscleral meshwork, and the juxtacanalicular or cribriform meshwork, whose outermost aspect is in communication with SC $[7,8]$ (figure 1b).

- The uveal meshwork is in direct communication with the aqueous humor. It is organized into fine, interwoven cords or pillars extending from the iris root and ciliary body to Schwalbe's line. These pillars consist of collagen and elastin fibers and are 
covered with TMC resting on a basement membrane. The meshwork of these pillars creates orifices allowing for outflow of aqueous.

- The corneoscleral meshwork, which represents the majority of the trabecular meshwork, is formed by a superimposition of joined lamellae traversed by orifices which extend and grow in number from the anterior wall of the scleral sulcus to the scleral spur. These lamellae consist of collagen and elastin fibers covered with a single layer of TMC resting on a basement membrane. The interlamellar spaces become more narrow near the juxtacanalicular meshwork but do not constitute an obstacle to aqueous outflow.

- The juxtacanalicular meshwork, the outermost portion of the posterior filtering trabecular meshwork, is histologically different from the other two portions of the trabecular meshwork. It is formed of loose, unstratified connective tissue and 2 to 5 layers of TMC dispersed within the extracellular matrix and arranged in a network with the help of their cytoplasmic extensions [3]. Its outermost portion corresponds to the endothelium of the inner wall of SC [9]. This is made up of a continuous layer of endothelial cells spaced at 15 to $20 \mathrm{~nm}$ intervals and connected by junctional complexes. Inside these cells, giant cytoplasmic vacuoles are described, as well as pores 0.5 to $2 \mu \mathrm{m}$ in diameter, allowing flow through the inner wall of Schlemm's canal [10].

The porosity of the posterior filtering trabecular meshwork decreases from inside to outside [11], but under physiologic conditions, the uveal and corneoscleral meshwork do not offer resistance to aqueous outflow.

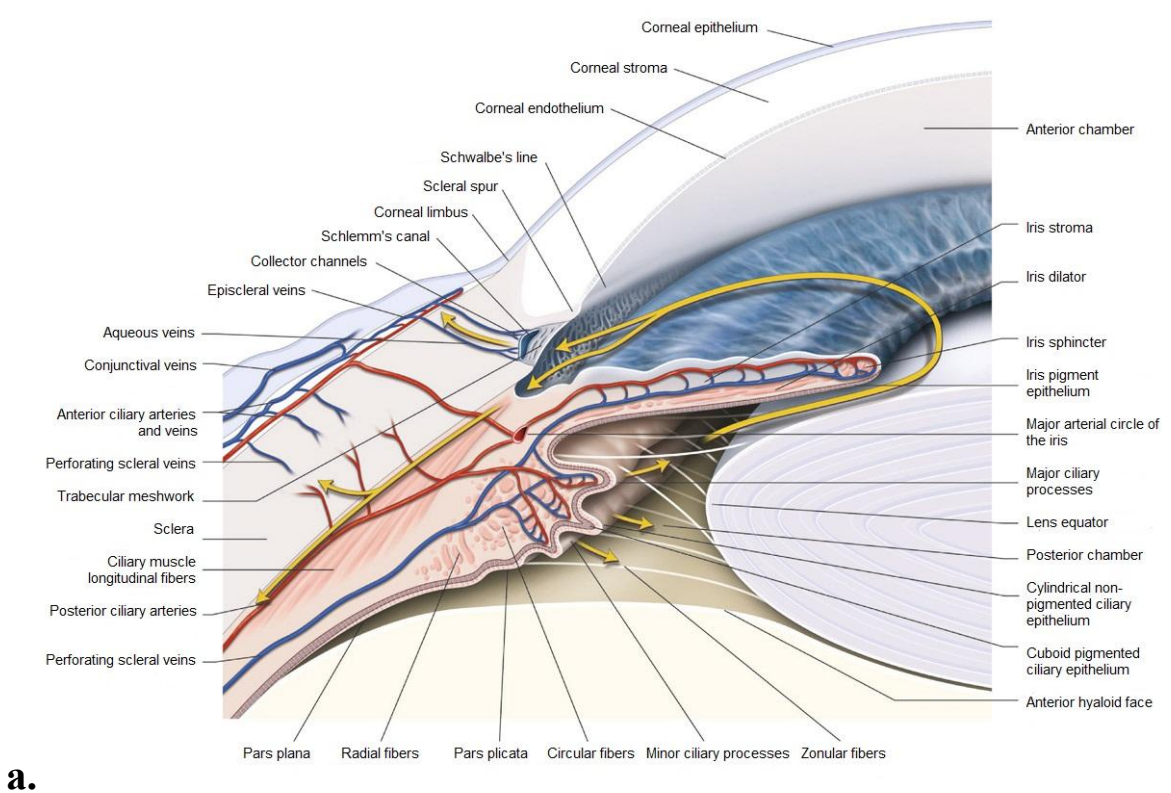

a. 


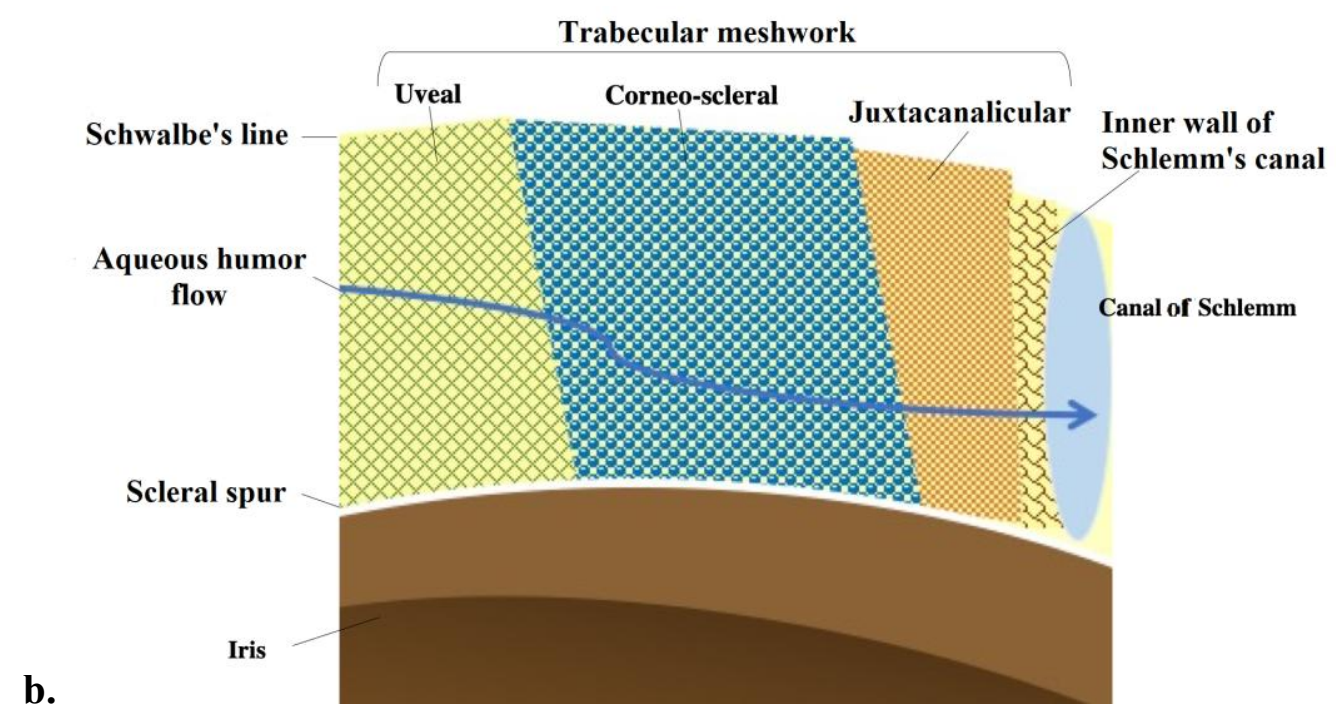

Figure 1: a. Schematic representation of aqueous flow within the anterior segment of the eye. (Rapport SFO 2014 : Glaucome primitif à angle ouvert J-P Renard [10])

b. Schematic of trabecular meshwork organization.

\section{Trabecular meshwork cells}

Trabecular meshwork cells (TMC) are special cells combining properties of endothelial cells, myofibroblasts and macrophages (figure 2). They are responsible for regulation of aqueous outflow resistance. The properties of TMC differ depending on their location within the trabecular meshwork and are summarized in table 1.

\begin{tabular}{|c|c|c|c|}
\hline Phenotype & Location & Cellular behavior & Role \\
\hline Endothelial & $\begin{array}{c}\text { Corneoscleral and } \\
\text { uveal portions } \\
\text { Round to oval, }\end{array}$ & Endothelium & $\begin{array}{c}\text { Maintenance of } \\
\text { permeability }\end{array}$ \\
\cline { 3 - 4 } & & & $\begin{array}{c}\text { Neutralization of reactive } \\
\text { oxygen species }\end{array}$ \\
\cline { 3 - 4 } & & Macrophage & $\begin{array}{c}\text { Biologic filter/ } \\
\text { phagocytosis }\end{array}$ \\
\cline { 3 - 4 } & & & Immune mediation \\
\hline Fibroblastic & Juxtacanalicular & Fibroblast & $\begin{array}{c}\text { ECM renewal/ } \\
\text { tissue repair }\end{array}$ \\
\cline { 3 - 4 } Elongated shape & & Smooth muscle cell & Contractility \\
\cline { 3 - 4 } & & & Mechanotransduction \\
\hline
\end{tabular}

Table 1: Phenotypes and properties of trabecular meshwork cells (TMC).

Functioning as endothelial cells in the corneoscleral and uveal portions, TMC produce large quantities of antithrombotic substances, such as heparin sulfate and tissue plasminogen activator (tPA)[12]. Similarly to endothelial cells, TMC in the inner portion appear to participate in mediation of inflammation. The hypothesis that these cells might play a role in antigen presentation was proposed in the 1990's when class I and II major histocompatibility 
complexes (MHC) were detected on frozen sections of trabecular meshwork and cultured TMC [13-16]. More recently, studies have shown that these cells may secrete a certain number of factors such as enzymes and cytokines which modulate trabecular cell and ECM functions. Shifera et al. reported that cultured human TMC secrete significant quantities of chemotactic cytokines IL-8, CXCL6 and MCP1 in the absence of any stimulation [17]. Secretion of these cytokines increased under the influence of the pro-inflammatory cytokines TNF $\alpha$ and IL1 $\beta$. They were also able to demonstrate the monocytes, apparently under the influence of these chemotactic signals, circulated through the trabecular meshwork [18]. TMC also have activity similar to that of macrophages for elimination of cellular debris present within the aqueous $[19,20]$. Consistent with their role in regulating aqueous outflow resistance, TMC in the juxtacanalicular region have both fibroblastic and contractile properties. Their phenotype is quite different, with a spindle-shaped morphology. They secrete a certain number of ECM proteins (collagens, fibronectin, elastin, fibrillins and proteoglycans) and their degradative enzymes (matrix metalloproteinases (MMP-1, -2, -3, -9, -12 , et -14$)$ ), so as to support continuous remodeling of the ECM [21]. They are contractile, expressing smooth muscle actin and myosin, which are important in mechanotransduction [3]. A number of authors have suggested the hypothesis that the non-filtering region of the trabecular meshwork, near Schwalbe's line, might serve as a niche for stem cells capable of dividing and recolonizing the trabecular meshwork after an injury [22,23].

a.

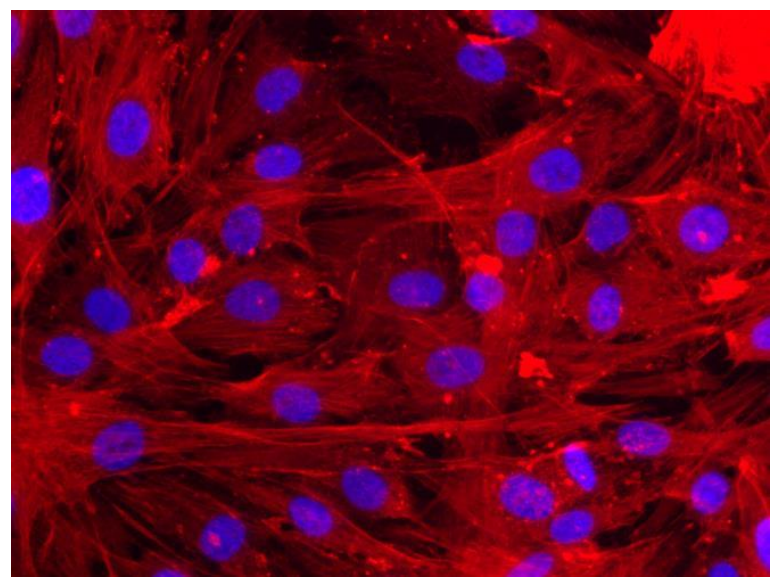

b.

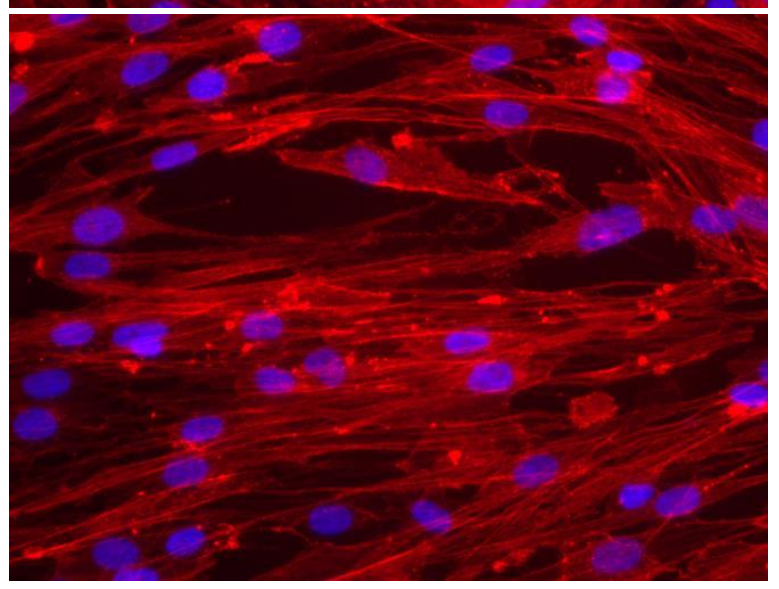

Figure 2: Human trabecular meshwork cells (TMC). The actin cytoskeleton is stained with phalloidin (red) and the nucleus with DAPI (blue). a. stellate morphology b. spindle morphology (200X). 


\section{Extracellular matrix (ECM)}

The ECM is made up of fibrillar components and an amorphous ground substance composed of collagens, hyaluronate and proteoglycans [24]. In the uveal and corneoscleral meshwork, the connective tissue and/or ECM lamellae are covered with TMC. In the juxtacanalicular region, the cells live relatively freely and are integrated within the ECM (figure 3) [25]. The juxtacanalicular tissue is composed of a network of elastic fibers, the cribriform plexus, which extends between the corneoscleral meshwork and the inner wall of SC. The elastic fibers of the cribriform plexus are composed of elastin fibers sheathed with a material containing type VI collagen, laminin and fibronectin, responsible for adherence of cells to their substrates [26]. The cribriform plexus fibers are connected to the SC endothelial cells by fine elastic fibrils emerging from the sheath material [27].

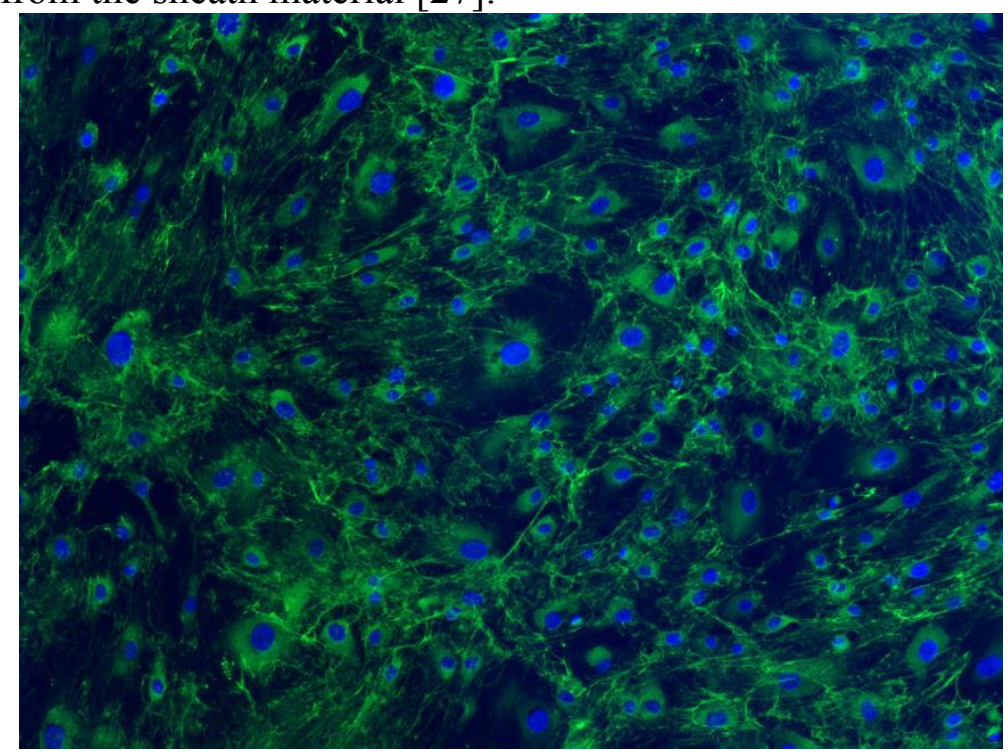

Figure 3: Human trabecular meshwork cells (TMC) within their extracellular matrix (ECM). The ECM is stained with an anti-fibronectin antibody (green) and the nuclei are stained with DAPI (blue) (100X magnification).

\section{Aqueous outflow and IOP regulation}

Aqueous exits the eye via two pathways: the primary pathway, trabecular, also known as conventional, (40-96\% of the outflow [28,29]), and the secondary pathway, known as uveoscleral. In trabecular outflow, the trabecular meshwork controls the IOP by regulating outflow of aqueous from the anterior chamber into the adjacent $\mathrm{SC}$, then into the aqueous vein collector channels and into the venous system (Figure 1). One may think of it as a selfcleaning biologic filter whose caliber can be more or less fine depending on various regulatory factors.

In man, $75 \%$ of aqueous outflow resistance occurs within the trabecular meshwork, in particular the juxtacanalicular portion, and $25 \%$ within SC [30].

Resistance is influenced by two contractile systems, that of the anterior portion of the ciliary muscle via tendinous extensions from the ciliary muscle traversing the cribriform trabecular meshwork and inserting into the wall of SC [31], and that due to myofibroblastic type 
contractile TMC. Thus, resistance is reduced by ciliary muscle contraction or by relaxation of the contractile cells within the trabecular outflow pathways.

Regulation of resistance occurs by a mechanism of cellular detection of stretching or deformation in the juxtacanalicular region of the trabecular meshwork [32]. The TMC in this region also secrete ECM proteins and degradative enzymes to support ECM remodeling. With input from cellular stretch receptors, adjustments in resistance thus occur through changes in ECM turnover: secretion and/or activation of proteinases, matrix cleavage, digestion of fragments and biosynthesis of its components [27].

TMC also possess adaptive properties such as mechanisms of intercellular adhesion, cellmatrix interactions, cellular contractility related to their actin cytoskeleton, and expression of water channels to facilitate rapid changes in cell volume [32].

\section{Trabecular degeneration in glaucoma}

\section{Primary open angle glaucoma}

In primary open angle glaucoma (POAG), trabecular aqueous outflow resistance is abnormally elevated [33]. Studies have shown that this increased resistance is related to a mechanism of trabecular stiffening involving senescence and apoptosis of TMC and remodeling of the ECM $[3,4,11,33,34]$. These changes are similar to age-related trabecular changes but seem to accelerate in glaucoma [35]. Thus, Tektas et al. have described a significant increase in thickness of the sheaths of the elastic fibers compared to the trabecular meshwork of normal subjects of the same age. On transverse sections, these appear as extracellular "plaques" and are known as "sheath-derived plaques" [33]. This increase is due to the fibrils and other ECM components adhering to the sheaths of the elastic fibers and their connections with the endothelium of the inner wall. In eyes with POAG, there is also a marked loss of TMC, which in spots leads to fusion and thickening of the trabecular lamellae [33].

A confocal microscopic study by Hamard et al. has shown a very significant decrease in cell density within the outer trabecular membrane (OTM) removed during non-penetrating deep sclerectomy (NPDS) in glaucomatous subjects compared to controls (figure 4). This cell loss involves the juxtacanalicular meshwork as well as a portion of the adjacent corneoscleral meshwork [36]. 


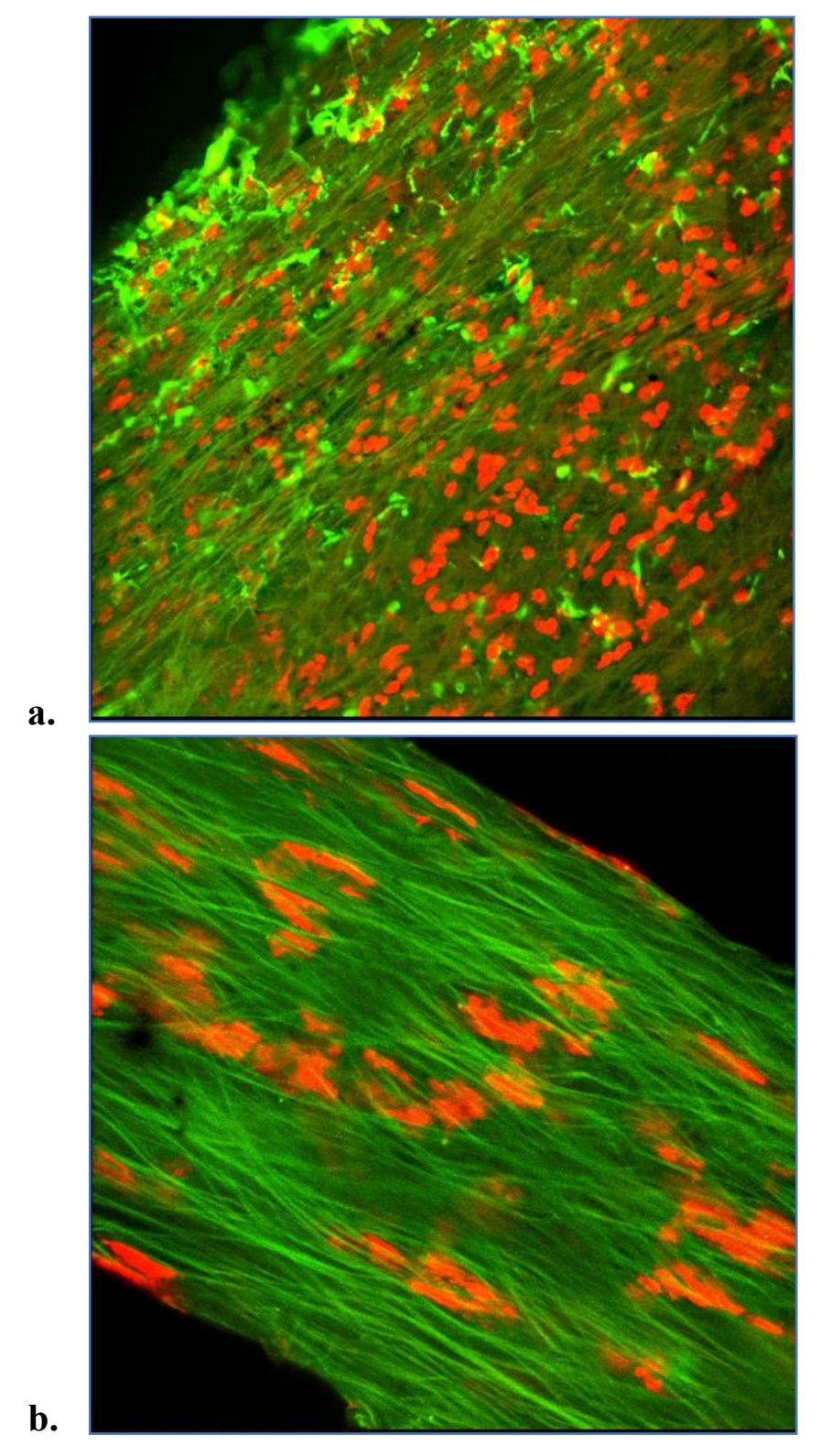

Figure 4: a. Confocal microscopic image of normal trabecular meshwork: the nuclei are stained red, elastin shows a mild green autofluorescence allowing visualization of the ECM, and the cells of the cribriform trabecular meshwork have a dendritic appearance and are strongly fluorescent after staining with an anti-vimentin antibody.

b. Glaucomatous trabecular meshwork on confocal microscopy: significant rarefaction of the trabecular meshwork cells (red) and major increase in ECM (autofluorescent green fibers) in the corneoscleral meshwork.

Tamm et al. have also described changes in juxtacanalicular connective tissue cells, which acquire contractile properties $(5,6)$. An augmentation and reorganization of the actin cytoskeleton is seen, as well as the ECM, leading to stiffening of the inner wall of SC [37]. 
Under the influence of transforming growth factor $\beta 2$ (TGF- $\beta 2$ ), changes are also seen in the trabecular meshwork itself. TGF- $\beta 2$ thus seems to play a significant role in the pathogenesis of POAG. It is a profibrotic cytokine known to be present in higher concentration in the aqueous of glaucoma patients [38]. The trabecular meshwork is an endogenous source of TGF- $\beta 2[39,40]$. Tripathi et al. were able to show that TGF- $\beta 2$ increased IOP by inducing synthesis by the TMC of certain matrix components not degradable by metalloproteinases $[41,42]$. These effects are mediated by induction of conventional TGF- $\beta 2$ signal cascades (SMAD pathways) as well as unconventional pathways (MAPK and Rho GTPase pathways) [40]. The conventional SMAD signaling pathways involve omnipresent signaling proteins with a number of downstream effectors implicated in, among others, healing of corneal scars and maintenance of the ocular immune privilege. The SMAD3 isoform is more systematically related to expression of mediators implicated in ocular hypertension. This implies that targeted inhibition of SMAD3 might be an interesting approach for glaucoma treatment [40]. Another approach might be that of SMAD7 modulation, a SMAD inhibitor with functions as an intracellular antagonist to TGF- $\beta$ signaling [43].

TGF- $\beta 2$ also appears to increase cellular rigidity by formation of Cross-linked Actin Networks (CLANs) via the Rho-GTPase pathway (figure 5) [39]. CLANs are cytoskeletal rearrangements changing cell shape and rigidity and thus their ability to respond to external signals. The cells of the trabecular outflow pathways would thus be stimulated by TGF- $\beta 2$ to take on an increasingly contractile phenotype, involving an increase in both the actin cytoskeleton and the surrounding fibrillar ECM.

Bone morphogenetic proteins (BMP) are a family of growth factors involved in regulation of the ECM and thus in regulation of aqueous outflow resistance. The BMP and TGF- $\beta$ signaling pathways have opposing antifibrotic and profibrotic roles. BMPs may thus degrade matrix deposits induced by TGF- $\beta 2$ [44]. It has been shown that the BMP antagonists, gremlin and noggin are more strongly expressed in glaucomatous TMC and provoke an increase in IOP in perfused anterior segments [45-47]. Gremlin also apparently blocks BMP4 repression of the fibronectin synthesis induced by TGF- $\beta[46,48]$. Deregulation of this factor, probably under the influence of mutations or induced genetic polymorphisms, may thus explain the overexpression of TGF in primary glaucoma.

Oxidative stress may also play a significant role in the pathophysiology of glaucoma. A meta-analysis published in 2016 reported that markers of oxidative stress were overexpressed in the serum and aqueous humor of glaucoma patients [49]. The production of reactive oxygen species (ROS) in the trabecular meshwork is both endogenous (generated by mitochondria) and exogenous. It may increase due to age, inflammation, light, infrared or ultraviolet exposure, or certain toxins. A disturbance in the pro-oxidant/antioxidant equilibrium in the aqueous humor results in an increase in the production of ROSs, thus altering the trabecular meshwork [50]. The ROSs damage proteins, lipids and DNA molecules; these processes are associated with cellular aging, chronic inflammation, apoptosis and cell death, releasing free radicals and resulting in a vicious circle. Within the trabecular meshwork, one sees a cessation of cell growth, a change in cellular permeability, 
rearrangements of the cytoskeleton of TMC, affecting their function and interactions with the ECM, and an accumulation of ECM [50,51]. Interestingly, it has been shown that TGF- $\beta 2$ provokes an increase in oxidative stress in human TMC. Pretreatment of TMC with antioxidants targeted to mitochondria (XJB-5-131 $(10 \mu \mathrm{M})$ or MitoQ $(10 \mathrm{nM}))$ decrease the TGF- $\beta 2$-mediated effects on SMAD-dependent transcriptional activity, including marked reductions in stress fibers and collagen expression [52].

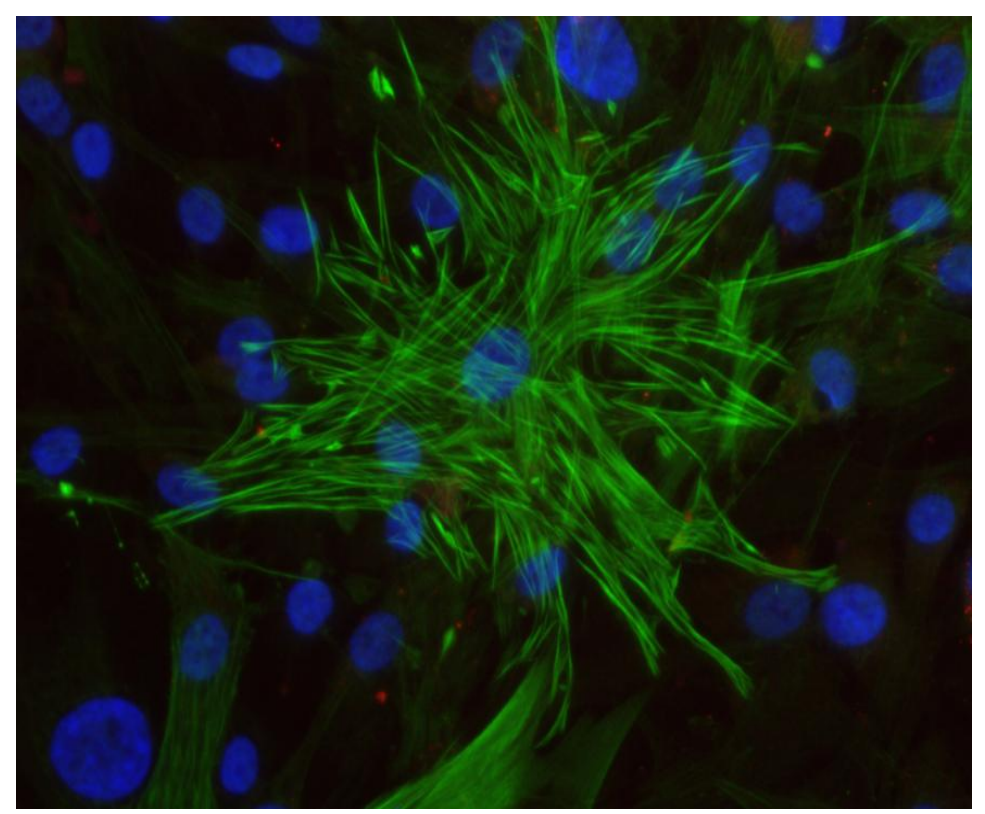

Figure 5: Cross-linked Actin Networks (CLANs) within human trabecular meshwork cells. Cytoskeletal rearrangement with interconnection of actin fibers leading to a change in cellular shape and rigidity. The actin cytoskeleton is stained with an anti-alpha-smooth muscle actin antibody (green) and the nucleus with DAPI (blue) (20X).

\section{Angle closure glaucoma}

In angle closure glaucoma, the mechanism of IOP elevation is explained by apposition of the iris to the trabecular meshwork, blocking aqueous outflow. However, in certain cases, even after removal of the trabecular block, the IOP remains elevated. On gonioscopy, peripheral anterior synechiae or pigment deposits may be seen on the trabecular meshwork.

A histologic study by Hamanaka et al. on trabecular specimens from patients undergoing trabeculectomy for angle closure has allowed observation of the damage to SC and the posterior trabecular meshwork [53]. Persistent contact between the trabecular meshwork and the iris or peripheral anterior synechiae blocking aqueous outflow result in SC involvement and occlusion. In the posterior portion of the trabecular meshwork, a loss of TMC is seen, along with a change in their mitochondrial function, with enlargement and fusion of the trabecular beams $[53,54]$. These mechanisms can explain persistent IOP elevation even once the angle is reopened in a patient with chronic angle closure glaucoma. 


\section{Steroid-induced glaucoma}

The primary finding in steroid-induced glaucoma is an accumulation of type IV collagen and fibronectin in the outer portion of the trabecular meshwork [55]. Also seen are an increase in mixed material with redundant basement membrane in a fingerprint pattern and unidentified fine fibrillar deposits arranged in bands in the subendothelial region of SC [33]. Steroids such as dexamethasone (DEX) are known to change the architecture of the trabecular meshwork by increasing trabecular cell rigidity. The matrix deposited by TMC under the influence of DEX is approximately 4 times more rigid, more organized, and shows a higher expression of ECM proteins generally implicated in glaucoma (decorin, myocilin and fibrillin) [56,57]. Biochemical and genetic studies have suggested that changes in trabecular myocilin expression, still known as the trabecular meshwork induced glucocorticoid response (TIGR), might play a role in the development of steroid-induced glaucoma [58,59]. It is interesting to note that the expression of this gene induced by exposure to steroids has a pro-apoptotic effect $[60,61]$. Consequently, the phagocytotic capacity of the cell population remaining in the trabecular meshwork is insufficient for effective filtration of the aqueous humor, thus increasing aqueous outflow resistance. Also in this case exists a mixed mechanism, both mechanical and degenerative, which may explain why the IOP does not always return to normal upon discontinuation of the steroid in steroid-induced glaucoma.

\section{Pigmentary glaucoma}

Pigment dispersion syndrome (PDS) is due to release of pigment from the posterior aspect of the iris into the anterior segment of the eye [62]. Blockage of the trabecular meshwork by this iris pigment may lead to its dysfunction and result in an IOP elevation. It is estimated that 25 to $50 \%$ of patients with PDS are at risk of developing ocular hypertension [63].

In this disease, a loss of TMC is seen, more significant than in POAG, probably related to toxicity of the pigment granule overload [33]. Exposure of the TMC to the pigment also apparently leads to a reduction in phagocytic ability and cellular migration, as well as an increase in the formation of stress fibers and cellular contraction $[64,65]$. Due to its role in the regulation of cell movement and shape, the Rho-ROCK signal pathway plays a central role in the formation and contraction of stress fibers, cellular adhesion, migration, phagocytosis and apoptosis. In a porcine pigmentary glaucoma model, the use of a ROCK inhibitor thus decreased IOP and increased phagocytosis [66,67].

\section{Pseudoexfoliative glaucoma}

Pseudoexfoliation syndrome corresponds to deposits of exfoliative material on certain organs such as the heart, vessels, lungs or meninges, but also in the anterior segment of the eye. This systemic degenerative fibrillopathy is multifactorial. Its risk factors are both genetic and environmental (age, exposure to ultraviolet) [68]. Pseudoexfoliative glaucoma results from the accumulation of extracellular fibrillar material and pigment in the trabecular meshwork and SC, leading to an increase in IOP. Immunohistochemical and mass spectrometry analyses 
have revealed that this pseudoexfoliative material is a highly glycosylated protein complex extremely resistant to degradation. This protein complex is a combination of basement membrane proteins, elastic fibers, TGF- $\beta$, metalloproteinases, chaperone proteins, complement proteins, type 1 lysyl-oxidase (LOXL1) and apolipoprotein E (ApoE) [69].

\section{Uveitic glaucoma}

In patients with uveitis, the pressure elevation seen may be due to the uveitis itself or may be a side effect of local steroid treatment. In fact, according to studies, $45 \%$ to $62 \%$ of uveitis patients are steroid responders [70]. It has been shown that elevated levels of trabecular proteins reduce trabecular outflow. Inflammatory cells, free radicals, and enzymes are also prone to raising IOP [71]. The main etiologies of hypertensive uveitides are Fuchs heterochromic iridocyclitis, herpes, Posner-Schlossman syndrome and juvenile idiopathic arthritis. Tektas et al. studied the trabecular meshwork of uveitic glaucoma patients removed during trabeculectomy [72]. They observed that there was an increase in ECM within the cribriform trabecular meshwork; the majority of the trabecular beams were thickened with a fibrillar material deposited between the TMC and basement membranes. Under the endothelium of the inner wall, there was an increase in "plaques" morphologically comparable to those seen in POAG patients. The trabecular meshwork of patients with juvenile idiopathic arthritis also showed accumulations of "plaques" on the inner wall and thickening of the trabecular beams, but this was due to a thickening of the basement membrane itself with collagen inclusions. The trabecular meshwork in herpes showed folds of basement membrane between the trabecular lamellae. The subendothelial region also showed an increase in plaques and fibrillar material. In addition, secondary iridocorneal angle closure may occur in uveitis by various mechanisms: posterior synechiae with pupillary block, peripheral anterior synechiae, forward rotation of the ciliary body [73]. Nearly $11 \%$ of patients develop peripheral anterior synechiae (PAS) secondary to inflammation [70]. The risk factors for development of PAS are: a narrow iridocorneal angle, use of mydriatics, and presence of posterior synechiae. The underlying mechanism is apparently precipitation of inflammatory cells and debris in the iridocorneal angle, leading to the formation of bridges between the peripheral iris and the sclera, resulting in the formation of synechiae.

\section{Trabecular toxicity of glaucoma medications}

Since glaucoma is a chronic pathology, it is important to consider the consequences of exposure to drops and their preservatives which are administered for the long term in these patients, especially benzalkonium chloride (BAK), which is the most widely utilized preservative in multidose glaucoma drops and which has shown toxic, pro-oxidant and proinflammatory effects on the ocular surface as well as the interior of the eye, particularly in the trabecular meshwork [74]. In fact, Brignole-Baudouin et al. have demonstrated in rabbits, with mass spectrometry imaging, that BAK may penetrate into the trabecular meshwork after repeated ocular instillation [75]. Baudouin et al. have also shown that BAK induces apoptosis, a stress oxidant, and expression of the cytokine, fractalkine. In addition, BAK participates in the cleavage of SDF1 (CXCL12) into a truncated form, SDF-1(5-67); SDF1 has protective effects via its classic GPCR receptor, CXCR4 and its truncated form are 
apparently responsible for cell death through involvement of another GPCR, CXCR3.

The same team also demonstrated a pro-apoptotic effect of BAK, with inhibition of $\mathrm{Bc} 12$, on cultured human TMC [76-78].

BAK also induces a pro-inflammatory effect, with increased expression of the proinflammatory cytokines interleukin-6 (IL-6) and IL-8 (CXCL8) in a three-dimensional trabecular meshwork model [79]. This work thus suggests that BAK aggravates all the characteristics of trabecular degeneration described in glaucoma: trabecular cell apoptosis, stress oxidants and induction of inflammatory chemokines.

\section{The trabecular meshwork as therapeutic target}

The only currently proven treatment strategy aimed at slowing the progression of glaucomatous optic neuropathy consists of lowering IOP [80-82]. This relies on medical, physical (such as lasers) or surgical approaches. The trabecular meshwork, as the main site of aqueous outflow resistance, is therefore widely targeted in glaucoma treatment.

\section{Medical approach}

While trabecular degeneration appears to be at the origin of glaucoma, medications acting directly on the trabecular meshwork are rare. Among medical glaucoma treatments, prostaglandin analogs are the most utilized, most effective, and best tolerated medications. The pressure lowering mechanism of action of the prostaglandins is still not perfectly understood. It appears to be mainly due to an increase in aqueous outflow through the uveoscleral pathway. However, more recent results might suggest a direct action of prostaglandins on the trabecular meshwork, with a remodeling of the trabecular ECM $[21,29,83]$. Kalouche et al. have shown that latanoprost, an analog of prostaglandin F2 $\alpha$, decreased trabecular ECM collagen accumulation but favored a contractile cell phenotype. However, butaprost, a prostanoid EP2 receptor antagonist, decreased both contraction of TMC and collagen deposition, thus inhibiting myofibroblastic cell transformation [84]. The concept of medications acting directly on the trabecular cytoskeleton has thus been proposed.

Rho-kinase (ROCK) inhibitors constitute a particularly interesting example, since they accurately target the profibrotic pathway which results in the trabecular ECM changes. The Rho/ROCK signal pathway plays an important role indeed in the modulation of the cytoskeleton and synthesis of the ECM [85]. The Rho family includes small proteins that bind to guanosine triphosphate (GTP), which regulate the shape, motility, proliferation and apoptosis of cells throughout the body. As is shown in the schematic in figure 6 , after binding of TGF- $\beta 2$ to its receptor, Rho-GTP activates its effector molecules (Rho-kinase ROCK 1 and 2). The ROCKs thus inhibit myosin light chain phosphatase by phosphorylating the myosinbinding subunit, thus inducing changes in the actin cytoskeleton. The ROCKs activate LIM kinases via phosphorylation, which stabilizes filamentous actin and reduces cellular migration. Activation of this pathway leads to increased aqueous outflow resistance, while inhibition of it decreases the IOP $[66,86]$. The Rho-kinase inhibitors represent a new 
treatment strategy in glaucoma, targeting the TGF- $\beta$ pathway that causes ECM changes [87]. A ROCK inhibitor, Ripasudil, has been approved by the Japanese health authorities for the treatment of glaucoma or ocular hypertension, as second-line therapy after standard treatment. The first study published on the efficacy of Ripasudil shows moderate efficacy on IOP, going from $15.1 \pm 4.6 \mathrm{mmHg}$ prior to treatment to $13.3 \pm 3.0 \mathrm{mmHg}$ at 24 months $(\mathrm{p}<0.05)$ [88]. Another molecule in the same family, Netarsudil 0.02\% (Rhopressa ${ }^{\circledR}$, Aerie Pharmaceuticals, Inc., USA), received FDA approval in December 2017 for lowering IOP in patients with POAG [89] and European market approval in late 2019. In three phase III trials in patients with elevated IOP, the ocular hypotensive efficacy of Netarsudil $0.02 \%$ instilled once a day met criteria of non-inferiority compared to timolol $0.5 \%$ instilled twice a day [90]. One may nonetheless be bothered by frequent adverse effects: blepharitis, conjunctival hyperemia, subconjunctival hemorrhages, cornea verticillata type corneal opacities [88,91,92]. The combination of a ROCK inhibitor with a prostaglandin has been proposed and appears to obtain synergistic results on IOP lowering, with IOP reductions of $30 \%$ or more seen in 59 to $65 \%$ of subjects treated with the combination of netarsudil and latanoprost, vs. 29 to $37 \%$ of subjects treated with latanoprost alone and 21 to $29 \%$ of subjects treated with netarsudil alone $(\mathrm{p}<0.0001)[93,94]$.

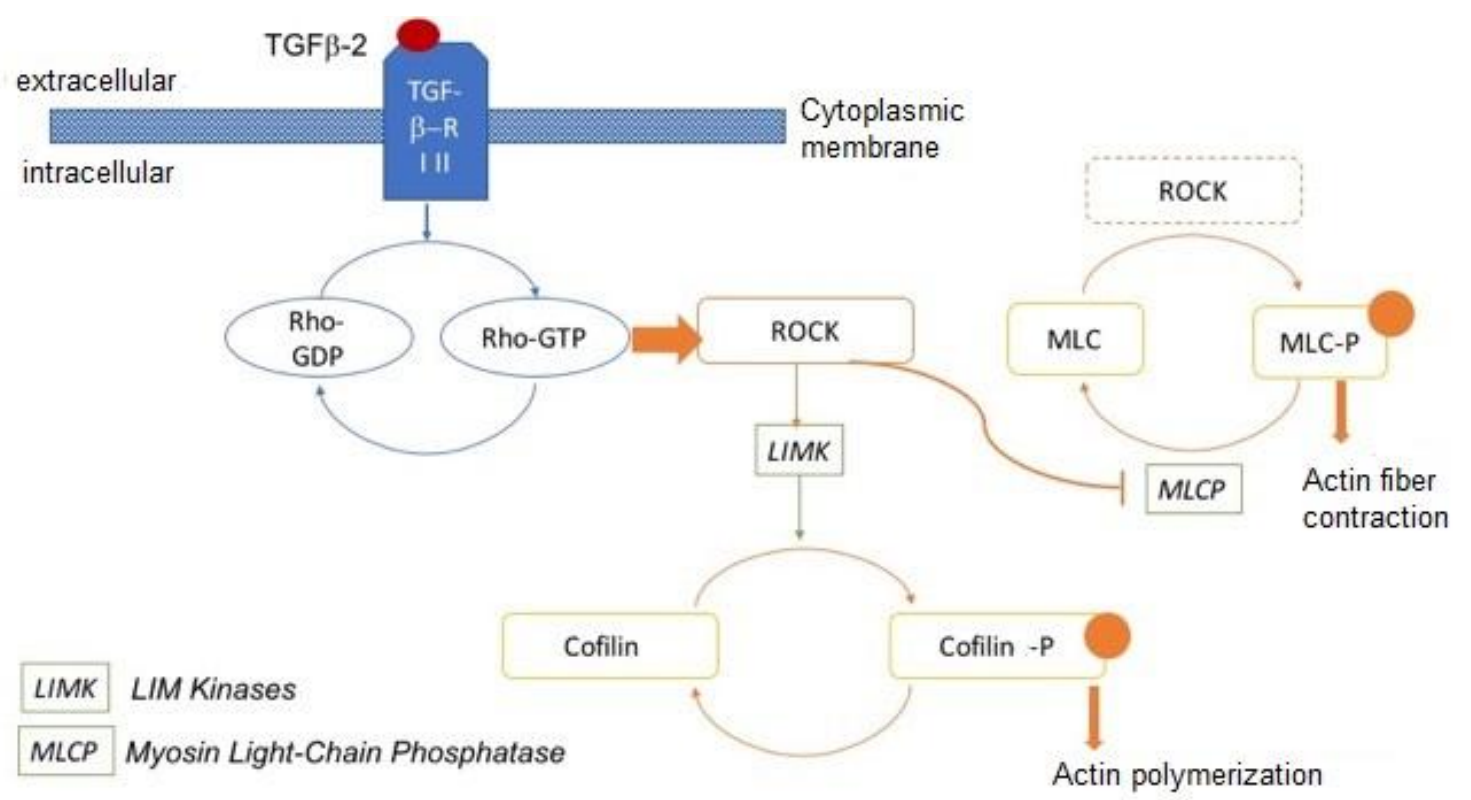

Figure 6: Rho-kinase signal pathway. The activated TGF $\beta$ receptor (TRF- $\beta$ RI-II) binds guanosine triphosphate (GTP) to the protein Rho. Rho-GTP activates its effector molecules, the ROCKs (Rho-kinases ROCK 1 and 2). The ROCKs inhibit myosin light chain phosphatase (MLCP). Phosphorylation of the binding subunit to myosin induces changes in the actin cytoskeleton. The ROCKs also activate LIM kinases, which phosphorylate cofilin, which stabilizes actin.

\section{Laser treatment}


Selective laser trabeculoplasty (SLT), described by Latina and Park in 1995 [95], is performed with a pulsed, frequency-doubled (Q-switched) Nd:YAG laser. It has been called "selective" due to its targeting of pigmented TMC while leaving the trabecular meshwork intact. The increase in aqueous outflow from the eye after an SLT may be explained by several mechanisms, notably mechanical traction on the uveoscleral trabecular meshwork and $\mathrm{SC}$, cellular mechanisms which stimulate cell division, and biochemical mechanisms which alter cytokines and stimulate the macrophage properties of the TMC [96]. A histologic study of eyes which had undergone SLT showed only minimal mechanical damage [97]. The intraocular pressure (IOP) lowering effect of SLT may thus be explained above all by biochemical and cellular changes more so than mechanical effects [98].

\section{Surgical treatment}

Since elevated IOP stems from a change in aqueous outflow, surgical glaucoma treatments aim to improve outflow through existing physiologic pathways or to divert the aqueous through new non-physiologic pathways (such as subconjunctival outflow).

\section{Filtering surgeries}

For IOP lowering, the surgeries most often performed in France are trabeculectomy [99] and non-penetrating deep sclerectomy (NPDS) [100]. These are both filtering surgeries, the principle of which is to create a pathway for aqueous outflow from the anterior chamber of the eye to a subconjunctival space (the filtering bleb) by bypassing all or part of the trabecular meshwork. Trabeculectomy consists of the en bloc removal of full thickness trabecular meshwork. It offers IOP lowering of approximately 46 to $51 \%$ at 2 years according to studies [101-103]. The NPDS technique was developed to minimize the complications of trabeculectomy. It consists of the selective removal of the outer trabecular membrane (juxtacanalicular trabecular meshwork and inner wall of SC), where the main component of increased aqueous outflow resistance is located. Cillino et al. [103] compared IOP lowering at one year between trabeculectomy and NPDS and found a decrease of $51 \%$ for trabeculectomy and $42.5 \%$ for NPDS. The rates of complications such as hypotony $(38.1 \%$ vs. $0 \%$ ) and hypothalamia ( $33.3 \%$ vs. $5.2 \%)$ were significantly lower in the NPDS group.

\section{Trabecular MIGS}

In the last several years, the options for surgical management of glaucoma have multiplied, in particular with the appearance of MIGS, or minimally invasive glaucoma surgeries. With these techniques, the goal of IOP lowering is more modest than with classic filtering surgery, but with lower risk of complications and a more rapid visual recovery. They are most often performed in association with cataract surgery. The MIGS utilize various pathways to encourage aqueous outflow: trabecular, suprachoroidal or subconjunctival.

The trabecular devices aim to re-establish the natural pathway for aqueous outflow from the anterior chamber to SC. These procedures are based on the fact that the juxtacanalicular portion is the site of greatest resistance to aqueous outflow in the majority of open angle glaucoma patients. The trabecular MIGS increase trabecular outflow by one or more of the four following mechanisms: 1 . Trabecular bypass and direct communication between the 
anterior chamber and SC by way of a stent; 2. Maintenance of the lumen of SC; 3. Dilation of the collector channels; 4. Surgical opening of the inner wall of the canal [104].

The iStent ${ }^{\circledR}$ and iStent Inject (Glaukos Corp., San Clemente, CA) are trabecular stents which act by locally bypassing the trabecular meshwork to empty into SC [105,106]. A limitation of this approach is that the stent may not necessarily be positioned near one of the 25 to 30 collector channels of SC. In addition, certain collector channels may be more active than others. The Hydrus Microstent ${ }^{\circledR}$ (Ivantis Inc., Irvine, CA) is an $8 \mathrm{~mm}$ long stent which is implanted in the nasal portion of SC. It acts by both opening and stretching the trabecular meshwork. It thus holds the SC lumen open [107]. Excimer Laser Trabeculotomy® (ELT) allow the creation of full thickness openings in the trabecular meshwork and inner wall of SC so as to decrease trabecular resistance [104]. The Kahook Dual Blade ${ }^{\circledR}$ (New World Medical Inc, Rancho Cucamonga, CA) works by incising the trabecular meshwork and inner wall of $\mathrm{SC}$ to open $90^{\circ}$ of the trabecular meshwork [108]. The Trabectome ${ }^{\circledR}$ (NeoMedix Corp., Tustin, CA) is a handpiece which makes it possible to perform an electrosurgical circumferential trabeculotomy for 60 to $120^{\circ}$ of the trabecular meshwork and inner wall of SC [104]. Ab interno canaloplasty aims to dilate SC by injecting viscoelastic device through a microcatheter introduced $a b$ interno through a goniotomy. It thus creates a microperforation in the trabecular meshwork which may increase its permeability [109]. Gonioscopy-assisted Transluminal Trabeculotomy (GATT) aims to insert the same illuminated catheter used for $a b$ interno canaloplasty into SC, but, once the catheter has been fed through the entire $360^{\circ}$, the two ends of the catheter are externalized to create a complete ab interno trabeculotomy [110]. The success of these trabecular MIGS may also be limited by postoperative scarring at the SC site. Finally, these procedures reduce juxtacanalicular resistance but do not reduce the distal sites more resistant to flow, such as elevated episcleral venous pressure, which may be more significant in certain patients. The postoperative IOP result after these procedures does not decrease below the episcleral venous pressure. This is why the efficacy of trabecular techniques is generally less than that of subconjunctival filtration techniques, which create a non-physiologic pathway for aqueous outflow [111].

\section{Perspectives}

\section{New techniques under investigation}

In clinical practice, examination of the trabecular meshwork relies on gonioscopy. The trabecular meshwork has a translucent appearance and is often dull gray or brown (figure 7a). The anterior portion of the trabecular meshwork is generally less pigmented and is considered the non-filtering portion of the meshwork. The posterior portion is larger in size and covers SC. The trabecular meshwork is pigmented and can accumulate pigment with age and specific ocular diseases such as pigment dispersion or pseudoexfoliation. Trauma, uveitis and surgery, including laser (iridotomy in particular) are also causes of pigment deposition in the angle. Clinical gonioscopy permits an appreciation of the openness of the angle, the amount of pigmentation, and anatomic features such as iris processes. New techniques of clinical investigation of the trabecular meshwork are being developed to more precisely image this 
key structure. Indeed, a better resolution, on the order of microns, would aid in understanding the changes brought on by aging of the trabecular meshwork and would allow evaluation of glaucoma medications targeting the trabecular meshwork so as to improve evaluation of the results and causes of failure of classic or minimally invasive glaucoma surgeries (MIGS). Optical coherence tomography (OCT) of the anterior segment provides certain details, but represents only a crude approach to the trabecular meshwork and SC (figure 7b). OCT coupled with gonioscopy offers resolution superior to goniophotography and also allows a more in depth investigation [112,113]. Thus, King et al. have developed a high-resolution imaging system based on an adaptive optics scanning laser ophthalmoscopic (AOSLO) system, originally conceived for retinal imaging, then coupled to a gonioscopic lens. This provides imaging of the trabecular meshwork on a micron scale in vivo in humans. The images obtained show the trabecular beams and endothelial cells [114]. The development of this technique could allow direct in vivo measurements, on a micron scale, of the changes occurring in the human trabecular meshwork in glaucoma as well as after a therapeutic procedure.

a.
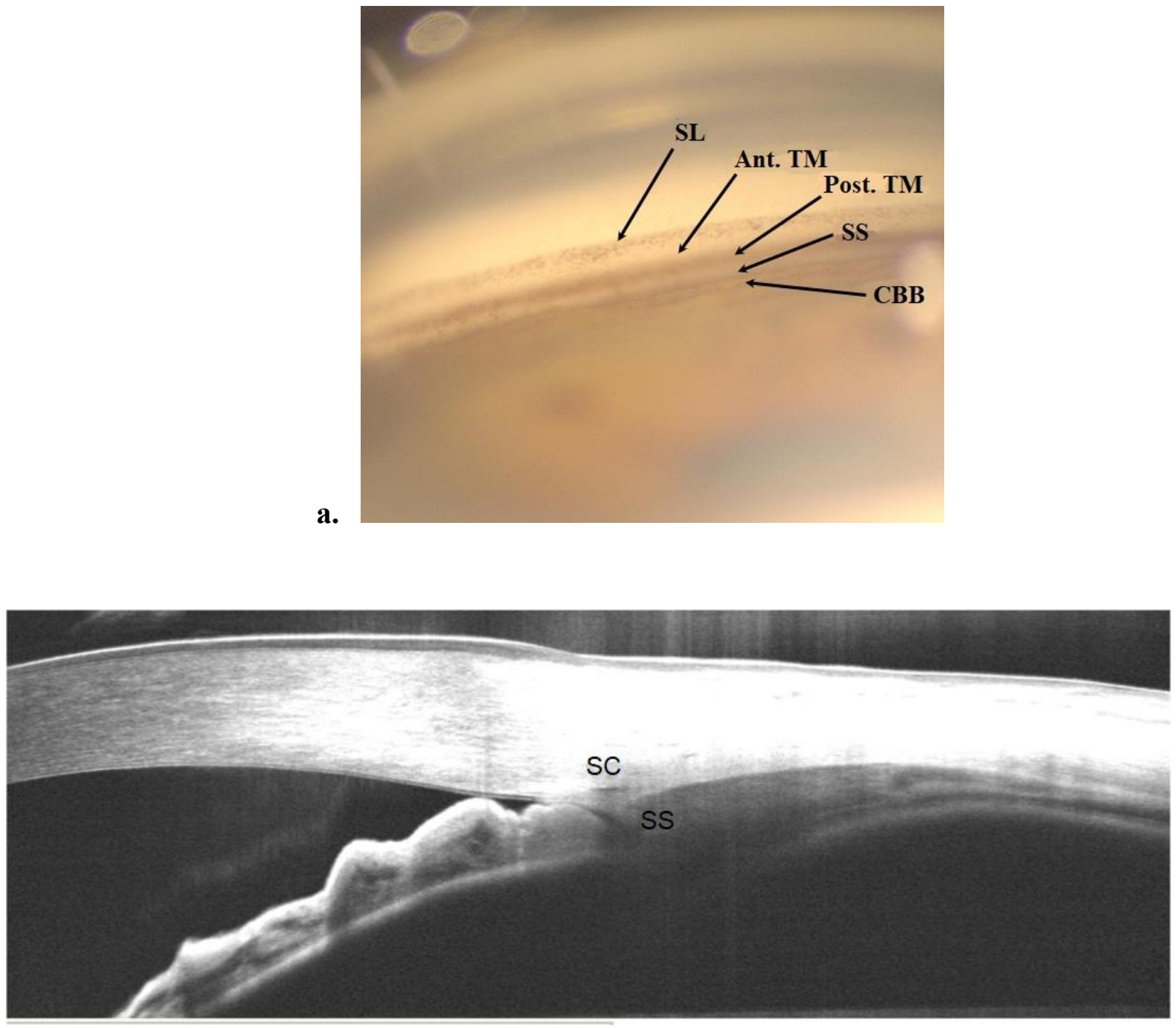

Figure 7: a. Goniophotograph of the iridocorneal angle. The anterior portion of the trabecular meshwork (ant. TM) is generally less pigmented; the posterior portion (post. TM) is larger in size and covers Schlemm's canal. The structures are only visible as bands 
delineated by pigmentation, and no fine anatomic structure is apparent. SL: Schwalbe's line; SS: scleral spur; CBB: ciliary body band.

b. View of the iridocorneal angle on anterior segment swept source OCT. SC: Schlemm's canal; SS: scleral spur

\section{Trabecular protection strategy}

Oxidative stress induces damage to the trabecular meshwork and is one of the pathophysiologic mechanisms at the origin of glaucoma [50]. Regulation of the oxidation/reduction balance thus constitutes a therapeutic approach, in the form of trabecular protection to prevent glaucoma [52,115]. Kalouche et al. have shown that activation of the E prostanoid sub-type 2 (EP2) receptors protects the endoplasmic reticulum from apoptosis induced by stress through a down-regulation of p53 [116]. Another therapeutic approach has been suggested by Denoyer et al. [78]: blockage of the interaction between the truncated form of CXCL12 (SDF1(5-67)) and CXCR3, which causes an induction of apoptosis in TMC. Treatment with a CXCR3 antagonist in a rat ocular hypertension model reduced IOP. Inhibition of this pathway might constitute an innovative therapeutic approach to restore trabecular function in patients with POAG.

\section{Cell therapy}

The decrease in number of TMC due to age and disease, accelerated apoptosis and senescence are associated with an increased resistance to aqueous outflow and thus an increase in IOP [34]. Due to their phagocytotic properties, TMC have the ability to eliminate debris potentially obstructing the trabecular filter, while they have a role in the synthesis and degradation of the components of the ECM [3]. The reduction in trabecular cell density thus affects renewal of the ECM and provokes the accumulation of debris, leading to increased outflow resistance in glaucomatous eyes. Theoretically, recolonization of the trabecular meshwork from stem cells could compensate for the cell loss in glaucomatous eyes and allow the trabecular meshwork to regain its function, thus reducing IOP [22,117].

Cell therapies based on stem cells for regeneration of the trabecular meshwork provide promising treatment perspectives. The trabecular stem cells are located in the region of the insertion of the trabecular meshwork into Schwalbe's line [118]. They can be isolated by cell sorting, monoclonal or sphere culture. Trabecular stem cells are multipotent, with the ability to colonize the trabecular region and differentiate into TMC in vivo. Other types of stem cells, such as adipocyte-derived stem cells, mesenchymal stem cells and induced pluripotent stem cells have been discovered for differentiation and regeneration of TMC [23]. Roubeix et al. have shown that, in the rat, injection of mesenchymal stem cells isolated from femoral bone marrow into the anterior chamber decreased IOP in an ocular hypertension model created by cauterization of the episcleral veins, and demonstrated a protective effect on the trabecular meshwork. They essentially observed an increase in trabecular cell survival with 
activation of the anti-apoptotic Akt pathway, relaxation of the TMC, and inhibition of the profibrotic phenotype induced by TGF- $\beta 2$ [119].

Another therapeutic approach is that of orientation of induced pluripotent stem cells (iPSC). Ding et al. have succeeded in obtaining iPSC cells with a phenotype close to that of human TMC after placing them in co-culture with human TMC [120]. Transplantation of these cells into perfused human anterior segments or into animal models stimulated proliferation of the endogenous TMC [121] and restored aqueous outflow, thus lowering IOP [122]. This type of iPSC based therapy is a promising strategy for IOP regulation in glaucoma patients [123].

\section{Conclusion}

The trabecular meshwork is a complex structure central to the pathophysiology of glaucoma. A deeper knowledge of the mechanisms at the origin of its degeneration and a better visualization of its architectural changes may change both the medical and surgical management of glaucoma. 


\section{Bibliographie}

[1] Tham Y-C, Li X, Wong TY, Quigley HA, Aung T, Cheng C-Y. Global prevalence of glaucoma and projections of glaucoma burden through 2040: a systematic review and metaanalysis. Ophthalmology 2014;121:2081-90.

[2] Gordon MO, Kass MA. The Ocular Hypertension Treatment Study: design and baseline description of the participants. Arch Ophthalmol 1999;117:573-83.

[3] Stamer WD, Clark AF. The many faces of the trabecular meshwork cell. Exp Eye Res 2017;158:112-23.

[4] Vranka JA, Kelley MJ, Acott TS, Keller KE. Extracellular matrix in the trabecular meshwork: intraocular pressure regulation and dysregulation in glaucoma. Exp Eye Res 2015;133:112-25.

[5] Cvekl A, Tamm ER. Anterior eye development and ocular mesenchyme. Bioessays 2004;26:374-86.

[6] Lütjen-Drecoll E. Functional morphology of the trabecular meshwork in primate eyes. Prog Retin Eye Res 1999;18:91-119.

[7] Gong H, Tripathi RC, Tripathi BJ. Morphology of the aqueous outflow pathway. Microsc Res Tech 1996;33:336-67.

[8] Buller C, Johnson D. Segmental variability of the trabecular meshwork in normal and glaucomatous eyes. Invest Ophthalmol Vis Sci 1994;35:3841-51.

[9] Johnson DH, Johnson M. How does nonpenetrating glaucoma surgery work? Aqueous outflow resistance and glaucoma surgery. J Glaucoma 2001;10:55-67.

[10] Renard J-P, Sellem E, Aptel F. Mécanismes de l'écoulement de l'humeur aqueuse. Glaucome primitif à angle ouvert. Elsevier Masson, 2014.

[11] Tamm ER. The trabecular meshwork outflow pathways: structural and functional aspects. Exp Eye Res 2009;88:648-55.

[12] Shuman MA, Polansky JR, Merkel C, Alvarado JA. Tissue plasminogen activator in cultured human trabecular meshwork cells. Predominance of enzyme over plasminogen activator inhibitor. Invest Ophthalmol Vis Sci 1988;29:401-5.

[13] Lynch MG, Peeler JS, Brown RH, Niederkorn JY. Expression of HLA class I and II antigens on cells of the human trabecular meshwork. Ophthalmology 1987;94:851-7.

[14] Latina M, Flotte T, Crean E, Sherwood ME, Granstein RD. Immunohistochemical staining of the human anterior segment. Evidence that resident cells play a role in immunologic responses. Arch Ophthalmol 1988;106:95-9.

[15] Coupland SE, Penfold P, Billson F, Hoffmann F. Immunohistochemistry study of the glaucomatous and normal human trabecular meshwork. Ger J Ophthalmol 1994;3:168-74.

[16] Tripathi BJ, Tripathi RC, Wong P, Raja S. Expression of HLA by the human trabecular meshwork and corneal endothelium. Exp Eye Res 1990;51:269-76.

[17] Shifera AS, Trivedi S, Chau P, Bonnemaison LH, Iguchi R, Alvarado JA. Constitutive secretion of chemokines by cultured human trabecular meshwork cells. Exp Eye Res 2010;91:42-7.

[18] Alvarado JA, Katz LJ, Trivedi S, Shifera AS. Monocyte modulation of aqueous outflow and recruitment to the trabecular meshwork following selective laser trabeculoplasty. Arch Ophthalmol 2010;128:731-7.

[19] Li X, Nagy JI, Li D, Acott TS, Kelley MJ. Gap junction connexin43 is a key element in mediating phagocytosis activity in human trabecular meshwork cells. Int J Physiol Pathophysiol Pharmacol 2020;12:25-31.

[20] Peotter JL, Phillips J, Tong T, Dimeo K, Gonzalez JM, Peters DM. Involvement of Tiam1, RhoG and ELMO2/ILK in Rac1-mediated phagocytosis in human trabecular meshwork cells. Exp Cell Res 2016;347:301-11.

[21] Weinreb RN, Robinson MR, Dibas M, Stamer WD. Matrix Metalloproteinases and 
Glaucoma Treatment. J Ocul Pharmacol Ther 2020.

[22] Yun H, Zhou Y, Wills A, Du Y. Stem Cells in the Trabecular Meshwork for Regulating Intraocular Pressure. J Ocul Pharmacol Ther 2016;32:253-60.

[23] Du Y, Roh DS, Mann MM, Funderburgh ML, Funderburgh JL, Schuman JS. Multipotent stem cells from trabecular meshwork become phagocytic TM cells. Invest Ophthalmol Vis Sci 2012;53:1566-75.

[24] Tamm ER, Braunger BM, Fuchshofer R. Chapter Eighteen - Intraocular Pressure and the Mechanisms Involved in Resistance of the Aqueous Humor Flow in the Trabecular Meshwork Outflow Pathways. In: Hejtmancik JF, Nickerson JM, editors. Progress in Molecular Biology and Translational Science, vol. 134, Academic Press; 2015, p. 301-14. [25] Knepper PA, Yue BY. Chapter 22 - Abnormal trabecular meshwork outflow. In: Levin LA, Albert DM, editors. Ocular Disease, Edinburgh: W.B. Saunders; 2010, p. 171-7.

[26] Ueda J, Wentz-Hunter K, Yue BYJT. Distribution of myocilin and extracellular matrix components in the juxtacanalicular tissue of human eyes. Invest Ophthalmol Vis Sci 2002;43:1068-76.

[27] Keller KE, Aga M, Bradley JM, Kelley MJ, Acott TS. Extracellular matrix turnover and outflow resistance. Exp Eye Res 2009;88:676-82.

[28] Fautsch MP, Johnson DH. Aqueous humor outflow: what do we know? Where will it lead us? Invest Ophthalmol Vis Sci 2006;47:4181-7.

[29] Winkler NS, Fautsch MP. Effects of prostaglandin analogues on aqueous humor outflow pathways. J Ocul Pharmacol Ther 2014;30:102-9.

[30] Grant WM. Further studies on facility of flow through the trabecular meshwork. AMA Arch Ophthalmol 1958;60:523-33.

[31] Rohen JW, Futa R, Lütjen-Drecoll E. The fine structure of the cribriform meshwork in normal and glaucomatous eyes as seen in tangential sections. Invest Ophthalmol Vis Sci 1981;21:574-85.

[32] Wang K, Read AT, Sulchek T, Ethier CR. Trabecular meshwork stiffness in glaucoma. Exp Eye Res 2017;158:3-12.

[33] Tektas O-Y, Lütjen-Drecoll E. Structural changes of the trabecular meshwork in different kinds of glaucoma. Exp Eye Res 2009;88:769-75.

[34] Liton PB, Challa P, Stinnett S, Luna C, Epstein DL, Gonzalez P. Cellular senescence in the glaucomatous outflow pathway. Exp Gerontol 2005;40:745-8.

[35] Liu B, McNally S, Kilpatrick JI, Jarvis SP, O’Brien CJ. Aging and ocular tissue stiffness in glaucoma. Surv Ophthalmol 2018;63:56-74.

[36] Hamard P, Valtot F, Sourdille P, Bourles-Dagonet F, Baudouin C. Confocal microscopic examination of trabecular meshwork removed during ab externo trabeculectomy. Br J Ophthalmol 2002;86:1046-52.

[37] Tian B, Gabelt BT, Geiger B, Kaufman PL. The role of the actomyosin system in regulating trabecular fluid outflow. Exp Eye Res 2009;88:713-7.

[38] Prendes MA, Harris A, Wirostko BM, Gerber AL, Siesky B. The role of transforming growth factor $\beta$ in glaucoma and the therapeutic implications. Br J Ophthalmol 2013;97:680 6.

[39] Webber HC, Bermudez JY, Sethi A, Clark AF, Mao W. Crosstalk between TGF $\beta$ and Wnt signaling pathways in the human trabecular meshwork. Exp Eye Res 2016;148:97-102. [40] Pervan CL. Smad-independent TGF- $\beta 2$ signaling pathways in human trabecular meshwork cells. Exp Eye Res 2017;158:137-45.

[41] Tripathi RC. Pathologic anatomy in the outflow pathway of aqueous humour in chronic simple glaucoma. Exp Eye Res 1977;25 Suppl:403-7.

[42] Picht G, Welge-Luessen U, Grehn F, Lütjen-Drecoll E. Transforming growth factor beta 2 levels in the aqueous humor in different types of glaucoma and the relation to filtering 
bleb development. Graefes Arch Clin Exp Ophthalmol 2001;239:199-207.

[43] Fuchshofer R, Stephan DA, Russell P, Tamm ER. Gene expression profiling of TGFbeta2- and/or BMP7-treated trabecular meshwork cells: Identification of Smad7 as a critical inhibitor of TGF-beta2 signaling. Exp Eye Res 2009;88:1020-32.

[44] Tovar-Vidales T, Fitzgerald AM, Clark AF. Human trabecular meshwork cells express BMP antagonist mRNAs and proteins. Exp Eye Res 2016;147:156-60.

[45] Hernandez H, Millar JC, Curry SM, Clark AF, McDowell CM. BMP and Activin Membrane Bound Inhibitor Regulates the Extracellular Matrix in the Trabecular Meshwork. Invest Ophthalmol Vis Sci 2018;59:2154-66.

[46] Wordinger RJ, Fleenor DL, Hellberg PE, Pang I-H, Tovar TO, Zode GS, et al. Effects of TGF-beta2, BMP-4, and gremlin in the trabecular meshwork: implications for glaucoma. Invest Ophthalmol Vis Sci 2007;48:1191-200.

[47] McDowell CM, Hernandez H, Mao W, Clark AF. Gremlin Induces Ocular Hypertension in Mice Through Smad3-Dependent Signaling. Invest Ophthalmol Vis Sci 2015;56:5485-92.

[48] Mody AA, Wordinger RJ, Clark AF. Role of ID Proteins in BMP4 Inhibition of Profibrotic Effects of TGF- $\beta 2$ in Human TM Cells. Invest Ophthalmol Vis Sci 2017;58:84959.

[49] Benoist d'Azy C, Pereira B, Chiambaretta F, Dutheil F. Oxidative and Anti-Oxidative Stress Markers in Chronic Glaucoma: A Systematic Review and Meta-Analysis. PLoS ONE 2016;11:e0166915.

[50] Zhao J, Wang S, Zhong W, Yang B, Sun L, Zheng Y. Oxidative stress in the trabecular meshwork (Review). Int J Mol Med 2016;38:995-1002.

[51] Nita M, Grzybowski A. The Role of the Reactive Oxygen Species and Oxidative Stress in the Pathomechanism of the Age-Related Ocular Diseases and Other Pathologies of the Anterior and Posterior Eye Segments in Adults. Oxid Med Cell Longev 2016;2016:3164734.

[52] Rao VR, Lautz JD, Kaja S, Foecking EM, Lukács E, Stubbs EB. MitochondrialTargeted Antioxidants Attenuate TGF- $\beta 2$ Signaling in Human Trabecular Meshwork Cells. Invest Ophthalmol Vis Sci 2019;60:3613-24.

[53] Hamanaka T, Kasahara K, Takemura T. Histopathology of the trabecular meshwork and Schlemm's canal in primary angle-closure glaucoma. Invest Ophthalmol Vis Sci 2011;52:8849-61.

[54] Sihota R, Goyal A, Kaur J, Gupta V, Nag TC. Scanning electron microscopy of the trabecular meshwork: understanding the pathogenesis of primary angle closure glaucoma. Indian J Ophthalmol 2012;60:183-8.

[55] Tawara A, Tou N, Kubota T, Harada Y, Yokota K. Immunohistochemical evaluation of the extracellular matrix in trabecular meshwork in steroid-induced glaucoma. Graefes Arch Clin Exp Ophthalmol 2008;246:1021-8.

[56] Clark AF, Brotchie D, Read AT, Hellberg P, English-Wright S, Pang I-H, et al. Dexamethasone alters F-actin architecture and promotes cross-linked actin network formation in human trabecular meshwork tissue. Cell Motil Cytoskeleton 2005;60:83-95.

[57] Raghunathan VK, Morgan JT, Park SA, Weber D, Phinney BS, Murphy CJ, et al. Dexamethasone Stiffens Trabecular Meshwork, Trabecular Meshwork Cells, and Matrix. Invest Ophthalmol Vis Sci 2015;56:4447-59.

[58] Polansky JR, Fauss DJ, Zimmerman CC. Regulation of TIGR/MYOC gene expression in human trabecular meshwork cells. Eye (Lond) 2000;14 ( Pt 3B):503-14.

[59] Filla MS, Liu X, Nguyen TD, Polansky JR, Brandt CR, Kaufman PL, et al. In Vitro Localization of TIGR/MYOC in Trabecular Meshwork Extracellular Matrix and Binding to Fibronectin. Invest Ophthalmol Vis Sci 2002;43:151-61. 
[60] Sakai H, Shen X, Koga T, Park B-C, Noskina Y, Tibudan M, et al. Mitochondrial association of myocilin, product of a glaucoma gene, in human trabecular meshwork cells. $\mathbf{J}$ Cell Physiol 2007;213:775-84.

[61] Yam GH-F, Gaplovska-Kysela K, Zuber C, Roth J. Aggregated myocilin induces russell bodies and causes apoptosis: implications for the pathogenesis of myocilin-caused primary open-angle glaucoma. Am J Pathol 2007;170:100-9.

[62] Campbell DG. Pigmentary dispersion and glaucoma. A new theory. Arch Ophthalmol 1979;97:1667-72.

[63] Scott A, Kotecha A, Bunce C, Balidis M, Garway-Heath DF, Miller MH, et al. YAG laser peripheral iridotomy for the prevention of pigment dispersion glaucoma a prospective, randomized, controlled trial. Ophthalmology 2011;118:468-73.

[64] Wang C, Dang Y, Loewen RT, Waxman S, Shah P, Xia X, et al. Impact of pigment dispersion on trabecular meshwork cells. Graefes Arch Clin Exp Ophthalmol 2019;257:121730.

[65] Dang Y, Waxman S, Wang C, Loewen RT, Sun M, Loewen NA. A porcine ex vivo model of pigmentary glaucoma. Sci Rep 2018;8:5468.

[66] Wang J, Liu X, Zhong Y. Rho/Rho-associated kinase pathway in glaucoma (Review). Int J Oncol 2013;43:1357-67.

[67] Dang Y, Wang C, Shah P, Waxman S, Loewen RT, Loewen NA. RKI-1447, a Rho kinase inhibitor, causes ocular hypotension, actin stress fiber disruption, and increased phagocytosis. Graefes Arch Clin Exp Ophthalmol 2019;257:101-9.

[68] Schweitzer C. [Pseudoexfoliation syndrome and pseudoexfoliation glaucoma]. J Fr Ophtalmol 2018;41:78-90.

[69] Challa P, Johnson WM. Composition of Exfoliation Material. J Glaucoma 2018;27 Suppl 1:S29-31.

[70] Sharon Y, Friling R, Luski M, Campoverde BQ, Amer R, Kramer M. Uveitic Glaucoma: Long-term Clinical Outcome and Risk Factors for Progression. Ocul Immunol Inflamm 2017;25:740-7.

[71] Baneke AJ, Lim KS, Stanford M. The Pathogenesis of Raised Intraocular Pressure in Uveitis. Current Eye Research 2016;41:137-49.

[72] Tektas O-Y, Heinz C, Heiligenhaus A, Hammer CM, Luetjen-Drecoll E. Morphological changes of trabeculectomy specimens in different kinds of uveitic glaucoma. Curr Eye Res 2011;36:442-8.

[73] Souissi K, Afrit MAE, Trojet S, Kraiem A. Étiopathogénie des modifications de la pression intraoculaire au cours des uvéites. /data/revues/01815512/00290004/456/2008.

[74] Baudouin C, Pisella PJ, Fillacier K, Goldschild M, Becquet F, De Saint Jean M, et al. Ocular surface inflammatory changes induced by topical antiglaucoma drugs: human and animal studies. Ophthalmology 1999;106:556-63.

[75] Brignole-Baudouin F, Desbenoit N, Hamm G, Liang H, Both J-P, Brunelle A, et al. A new safety concern for glaucoma treatment demonstrated by mass spectrometry imaging of benzalkonium chloride distribution in the eye, an experimental study in rabbits. PLoS ONE 2012;7:e50180.

[76] Hamard P, Blondin C, Debbasch C, Warnet J-M, Baudouin C, Brignole F. In vitro effects of preserved and unpreserved antiglaucoma drugs on apoptotic marker expression by human trabecular cells. Graefes Arch Clin Exp Ophthalmol 2003;241:1037-43.

[77] Baudouin C, Denoyer A, Desbenoit N, Hamm G, Grise A. In vitro and in vivo experimental studies on trabecular meshwork degeneration induced by benzalkonium chloride (an American Ophthalmological Society thesis). Trans Am Ophthalmol Soc 2012;110:40-63.

[78] Denoyer A, Godefroy D, Célérier I, Frugier J, Degardin J, Harrison JK, et al. CXCR3 antagonism of SDF-1(5-67) restores trabecular function and prevents retinal 
neurodegeneration in a rat model of ocular hypertension. PLoS ONE 2012;7:e37873.

[79] Bouchemi M, Roubeix C, Kessal K, Riancho L, Raveu A-L, Soualmia H, et al. Effect of benzalkonium chloride on trabecular meshwork cells in a new in vitro 3D trabecular meshwork model for glaucoma. Toxicol In Vitro 2017;41:21-9.

[80] Kass MA, Heuer DK, Higginbotham EJ, Johnson CA, Keltner JL, Miller JP, et al. The Ocular Hypertension Treatment Study: a randomized trial determines that topical ocular hypotensive medication delays or prevents the onset of primary open-angle glaucoma. Arch Ophthalmol 2002;120:701-13; discussion 829-830.

[81] Heijl A, Leske MC, Bengtsson B, Hyman L, Bengtsson B, Hussein M, et al. Reduction of intraocular pressure and glaucoma progression: results from the Early Manifest Glaucoma Trial. Arch Ophthalmol 2002;120:1268-79.

[82] The Advanced Glaucoma Intervention Study (AGIS): 7. The relationship between control of intraocular pressure and visual field deterioration. The AGIS Investigators. Am J Ophthalmol 2000;130:429-40.

[83] Bahler CK, Howell KG, Hann CR, Fautsch MP, Johnson DH. Prostaglandins Increase Trabecular Meshwork Outflow Facility in Cultured Human Anterior Segments. Am J Ophthalmol 2008;145:114-9.

[84] Kalouche G, Beguier F, Bakria M, Melik-Parsadaniantz S, Leriche C, Debeir T, et al. Activation of Prostaglandin FP and EP2 Receptors Differently Modulates Myofibroblast Transition in a Model of Adult Primary Human Trabecular Meshwork Cells. Invest Ophthalmol Vis Sci 2016;57:1816-25.

[85] Amano M, Nakayama M, Kaibuchi K. Rho-kinase/ROCK: A key regulator of the cytoskeleton and cell polarity. Cytoskeleton (Hoboken) 2010;67:545-54.

[86] Pattabiraman PP, Rao PV. Mechanistic basis of Rho GTPase-induced extracellular matrix synthesis in trabecular meshwork cells. Am J Physiol, Cell Physiol 2010;298:C749763.

[87] Torrejon KY, Papke EL, Halman JR, Bergkvist M, Danias J, Sharfstein ST, et al. TGF $\beta 2$-induced outflow alterations in a bioengineered trabecular meshwork are offset by a rho-associated kinase inhibitor. Sci Rep 2016;6.

[88] Maruyama Y, Ikeda Y, Mori K, Yoshii K, Ueno M, Sotozono C, et al. Safety and Efficacy of Long-Term Ripasudil 0.4\% Instillation for the Reduction of Intraocular Pressure in Japanese Open-Angle Glaucoma Patients. J Ocul Pharmacol Ther 2020.

[89] US Department of Health and Human Services, Food and Drug Administration. Rhopressa approcal letter 208254. 2017.

[90] Kopczynski CC, Heah T. Netarsudil ophthalmic solution $0.02 \%$ for the treatment of patients with open-angle glaucoma or ocular hypertension. Drugs Today 2018;54:467-78. [91] Serle JB, Katz LJ, McLaurin E, Heah T, Ramirez-Davis N, Usner DW, et al. Two Phase 3 Clinical Trials Comparing the Safety and Efficacy of Netarsudil to Timolol in Patients With Elevated Intraocular Pressure: Rho Kinase Elevated IOP Treatment Trial 1 and 2 (ROCKET-1 and ROCKET-2). Am J Ophthalmol 2018;186:116-27.

[92] Sakamoto E, Ishida W, Sumi T, Kishimoto T, Tada K, Fukuda K, et al. Evaluation of offset of conjunctival hyperemia induced by a Rho-kinase inhibitor; 0.4\% Ripasudil ophthalmic solution clinical trial. Sci Rep 2019;9:3755.

[93] Asrani S, Bacharach J, Holland E, McKee H, Sheng H, Lewis RA, et al. Fixed-Dose Combination of Netarsudil and Latanoprost in Ocular Hypertension and Open-Angle Glaucoma: Pooled Efficacy/Safety Analysis of Phase 3 MERCURY-1 and -2. Adv Ther 2020. [94] Radell JE, Serle JB. Netarsudil/latanoprost fixed-dose combination for the treatment of open-angle glaucoma or ocular hypertension. Drugs Today 2019;55:563-74.

[95] Latina MA, Park C. Selective targeting of trabecular meshwork cells: in vitro studies of pulsed and CW laser interactions. Exp Eye Res 1995;60:359-71. 
[96] Alvarado JA, Alvarado RG, Yeh RF, Franse-Carman L, Marcellino GR, Brownstein MJ. A new insight into the cellular regulation of aqueous outflow: how trabecular meshwork endothelial cells drive a mechanism that regulates the permeability of Schlemm's canal endothelial cells. Br J Ophthalmol 2005;89:1500-5.

[97] Kramer TR, Noecker RJ. Comparison of the morphologic changes after selective laser trabeculoplasty and argon laser trabeculoplasty in human eye bank eyes. Ophthalmology 2001;108:773-9.

[98] Latina MA, de Leon JMS. Selective laser trabeculoplasty. Ophthalmol Clin North Am 2005;18:409-19, vi..

[99] Landers J, Martin K, Sarkies N, Bourne R, Watson P. A twenty-year follow-up study of trabeculectomy: risk factors and outcomes. Ophthalmology 2012;119:694-702.

[100] Hamard P, Lachkar Y. [Non penetrating filtering surgery, evolution and results]. J Fr Ophtalmol 2002;25:527-36.

[101] Kirwan JF, Lockwood AJ, Shah P, Macleod A, Broadway DC, King AJ, et al. Trabeculectomy in the 21st Century: A Multicenter Analysis. Ophthalmology 2013;120:2532-9.

[102] Gedde SJ, Feuer WJ, Shi W, Lim KS, Barton K, Goyal S, et al. Treatment Outcomes in the Primary Tube Versus Trabeculectomy Study after 1 Year of Follow-up. Ophthalmology 2018;125:650-63.

[103] Cillino S, Di Pace F, Casuccio A, Cillino G, Lodato G. Deep sclerectomy versus trabeculectomy with low-dosage mitomycin C: four-year follow-up. Ophthalmologica 2008;222:81-7.

[104] Andrew NH, Akkach S, Casson RJ. A review of aqueous outflow resistance and its relevance to microinvasive glaucoma surgery. Surv Ophthalmol 2019.

[105] Lavia C, Dallorto L, Maule M, Ceccarelli M, Fea AM. Minimally-invasive glaucoma surgeries (MIGS) for open angle glaucoma: A systematic review and meta-analysis. PLoS ONE 2017;12:e0183142.

[106] Wellik SR, Dale EA. A review of the iStent(®) trabecular micro-bypass stent: safety and efficacy. Clin Ophthalmol 2015;9:677-84.

[107] Pfeiffer N, Garcia-Feijoo J, Martinez-de-la-Casa JM, Larrosa JM, Fea A, Lemij H, et al. A Randomized Trial of a Schlemm's Canal Microstent with Phacoemulsification for Reducing Intraocular Pressure in Open-Angle Glaucoma. Ophthalmology 2015;122:1283-93. [108] Dorairaj SK, Kahook MY, Williamson BK, Seibold LK, ElMallah MK, Singh IP. A multicenter retrospective comparison of goniotomy versus trabecular bypass device implantation in glaucoma patients undergoing cataract extraction. Clin Ophthalmol 2018;12:791-7.

[109] Körber N. [Canaloplasty ab interno - a Minimally Invasive Alternative]. Klin Monbl Augenheilkd 2017;234:991-5.

[110] Grover DS, Godfrey DG, Smith O, Feuer WJ, Montes de Oca I, Fellman RL. Gonioscopy-assisted transluminal trabeculotomy, ab interno trabeculotomy: technique report and preliminary results. Ophthalmology 2014;121:855-61.

[111] Richter GM, Coleman AL. Minimally invasive glaucoma surgery: current status and future prospects. Clin Ophthalmol 2016;10:189-206.

[112] Perinchery SM, Shinde A, Fu CY, Jeesmond Hong XJ, Baskaran M, Aung T, et al. High resolution iridocorneal angle imaging system by axicon lens assisted gonioscopy. Sci Rep 2016;6:30844.

[113] Yasuno Y, Yamanari M, Kawana K, Miura M, Fukuda S, Makita S, et al. Visibility of trabecular meshwork by standard and polarization-sensitive optical coherence tomography. J Biomed Opt 2010;15:061705.

[114] King BJ, Burns SA, Sapoznik KA, Luo T, Gast TJ. High-Resolution, Adaptive Optics 
Imaging of the Human Trabecular Meshwork In Vivo. Transl Vis Sci Technol 2019;8:5. [115] Lin C, Wu X. Curcumin Protects Trabecular Meshwork Cells From Oxidative Stress. Invest Ophthalmol Vis Sci 2016;57:4327-32.

[116] Kalouche G, Boucher C, Coste A, Debussche L, Orsini C, Baudouin C, et al. Prostaglandin EP2 receptor signaling protects human trabecular meshwork cells from apoptosis induced by ER stress through down-regulation of p53. Biochim Biophys Acta 2016;1863:2322-32.

[117] Wang EX, Jiang X. Stem cells from trabecular meshwork cells can secrete extracellular matrix. Biochem Biophys Res Commun 2020;523:522-6.

[118] Kelley MJ, Rose AY, Keller KE, Hessle H, Samples JR, Acott TS. Stem cells in the trabecular meshwork: present and future promises. Exp Eye Res 2009;88:747-51.

[119] Roubeix C, Godefroy D, Mias C, Sapienza A, Riancho L, Degardin J, et al. Intraocular pressure reduction and neuroprotection conferred by bone marrow-derived mesenchymal stem cells in an animal model of glaucoma. Stem Cell Res Ther 2015;6:177.

[120] Ding QJ, Zhu W, Cook AC, Anfinson KR, Tucker BA, Kuehn MH. Induction of Trabecular Meshwork Cells From Induced Pluripotent Stem Cells. Invest Ophthalmol Vis Sci 2014;55:7065-72.

[121] Zhu W, Godwin CR, Cheng L, Scheetz TE, Kuehn MH. Transplantation of iPSC-TM stimulates division of trabecular meshwork cells in human eyes. Sci Rep 2020;10:2905.

[122] Zhu W, Jain A, Gramlich OW, Tucker BA, Sheffield VC, Kuehn MH. Restoration of Aqueous Humor Outflow Following Transplantation of iPSC-Derived Trabecular Meshwork Cells in a Transgenic Mouse Model of Glaucoma. Invest Ophthalmol Vis Sci 2017;58:205462.

[123] Castro A, Du Y. Trabecular Meshwork Regeneration - A Potential Treatment for Glaucoma. Curr Ophthalmol Rep 2019;7:80-8. 